in vivo $34: 3247-3254(2020)$

doi:10.21873/invivo.12161

\title{
SMN Protein Contributes to Skeletal Muscle Cell Maturation Via Caspase-3 and Akt Activation
}

\author{
SHIORI ANDO, MIRUTO TANAKA, NAOKI CHINEN, \\ SHINSUKE NAKAMURA, MASAMITSU SHIMAZAWA and HIDEAKI HARA \\ Molecular Pharmacology, Department of Biofunctional Evaluation, \\ Gifu Pharmaceutical University, Gifu, Japan
}

\begin{abstract}
Background/Aim: In spinal muscular atrophy (SMA), systemic deficiency of survival motor neurons (SMN) caused by loss or mutation of SMN1 leads to SMA symptoms. SMA was, for a long time, considered as a selective motorneuron disease. However, accumulated evidence suggests that skeletal muscle cells are affected by low levels of SMN protein. The purpose of this study was to elucidate the function of SMN protein in skeletal cell differentiation and maturation. Materials and Methods: In SMN 17 mice, which exhibit a systemic reduction of SMN protein, muscle atrophy was evaluated. To direct the effect of SMN against muscle cells, SMN functions were examined by knockdown of SMN in mouse myoblasts cell line C2C12 using siRNA. Results: SMNA7 mice showed muscle atrophy accompanied by decreased both expression of a myogenesis marker and a proliferating marker. In SMN-knockdown myoblasts, early expression of myosin heavy chain and reduced multinuclear myotube formation were found. Decreased caspase-3 activity and reduced phosphorylation of Akt were observed at an early stage of differentiation in SMN-knockdown myoblasts. Conclusion: A critical role of SMN protein in muscle cell differentiation via caspase-3 and Akt activation was shown.
\end{abstract}

Spinal muscular atrophy (SMA) is an inherited neuromuscular disease caused by loss or mutation of the survival motor neuron 1 (SMN1) gene and subsequent decrease of the SMN protein (1). SMA is characterized by progressive loss of motor neurons and skeletal muscle

This article is freely accessible online.

Correspondence to: Masamitsu Shimazawa, Ph.D., Molecular Pharmacology, Department of Biofunctional Evaluation, Gifu Pharmaceutical University, 1-25-4 Daigaku-nishi, Gifu 501-1196, Japan. Tel: +81 582308100, Fax: +81 582308105, e-mail: shimazawa@gifu-pu.ac.jp

Key Words: Myotube formation, skeletal muscles, spinal muscular atrophy, survival motor neurons. atrophy (2, 3). Humans possess two highly homologous genes that encode SMN protein: SMN1 and SMN2 on chromosome 5q11.2-13.3 (4). SMN1 produces almost the full length of SMN, which includes exon 7, but SMN2 mainly produces an unstable SMN protein that lacks exon 7 (SMN $\Delta 7)$ following alternative splicing $(5,6)$. Therefore, mutation or deletion of SMN1 leads to systemic SMN protein deficiency. The SMN protein plays important roles in mRNA splicing (7) and mRNA transport (8). However, the critical reason why SMN protein is responsible for SMA pathology is still unclear.

SMA was, for a long time, considered as a selective motorneuron disease. However, the effect of SMN up-regulation limited to the central nervous system was inferior to systemic SMN protein up-regulation for improving the phenotype of SMA model mice (9). Many studies have suggested that different organs including skeletal muscle, heart, and liver take part in the SMA phenotype due to systemic loss of the SMN protein. In particular, SMN protein in skeletal muscle is considered to have a strong relationship to SMA pathology. In SMN $\Delta 7$ mice, which exhibit a systemic reduction of SMN protein, postnatal muscle fibers growth was impaired in size, with a reduction in muscle fibers expressing fast myosin and an increase in the proportion of muscle fibers expressing the embryonic isoform of myosin heavy chain (10). Furthermore, Cifuentes-Diaz, et al. (11) reported that genetic deletion of murine SMN exon 7 restricted to skeletal muscle leads to severe skeletal muscle atrophy. Skeletal muscle satellite cells extracted from SMA model mice exhibit reduced efficiency in forming myotubes (12), and SMN-knockdown C2C12 cells, an immortalized mouse myoblast cell line, have decreased fusion ability (13). Moreover, SMN-deficient myotubes extracted from SMA patient biopsies are smaller compared to controls (14). These reports suggest that the SMN protein plays an important role in the maturation of skeletal muscle cells by cell-autonomous mechanisms. However, the fundamental function of the SMN protein underlying the maturation of skeletal muscle cells is still unknown. The purpose of the present study was to elucidate the function of SMN protein in skeletal cell differentiation and maturation. 


\section{Material and Methods}

Animals. As a moderate type II SMA animal model, heterozygous SMN $\Delta 7$ mice $\left(m S m n^{+/-}, S M N 2^{+/+}, S M N \Delta 7^{+/+}\right.$; stock No: 005025) were purchased as breeder pairs from Jackson Laboratory (Bar Harbor, ME, USA). To generate the homozygous SMN $\Delta 7$ mice $\left(m S m n^{-/}, S M N 2^{+/+}, S M N \Delta 7^{+/+}\right)$, the heterozygous SMN $\Delta 7$ mice were cross-breeded. All animal experiments were conducted with approvals of the Institutional Animal Care and Use Committee, and the Bioethics and Biosafety Committee of Gifu Pharmaceutical University. To identify wild-type $\left(m S m n^{+/+}, S M N 2^{+/+}, \operatorname{SMN} \Delta 7^{+/+}\right)$, heterozygous SMN $\Delta 7\left(m S m n^{+/-}, S M N 2^{+/+}, S M N \Delta 7^{+/+}\right)$, and homozygous SMN $\Delta 7\left(m S m n^{-/-}, S M N 2^{+/+}, S M N \Delta 7^{+/+}\right)$mice, the transgene genotypes were determined by PCR assays of tail DNA. The target gene was amplified by 35 cycles of PCR using the following 3 primers as our previous procedure (15):

5'-CTCCGGGATATTGGGATTG -3'

5'-GGTAACGCCAGGGTTTTCC-3'

5'-TTTCTTCTGGCTGTGCCTTT-3'

In this study, we used homozygous SMN $\Delta 7\left(\mathrm{mSmn}^{-/-}, \mathrm{SMN2} 2^{+/+}\right.$, $S M N \Delta 7^{+++}$) mice as SMA model mice, and compared them with wild-type $\left(\mathrm{mSmn}^{+/+}, \mathrm{SMN}^{+/+}, \mathrm{SMN} \Delta 7^{+/+}\right)$mice.

Histological analysis of gastrocnemius. Gastrocnemius were isolated from mice at 11 days of age and prepared histological sections in accordance with our previous report (16). Briefly, under anesthesia using sodium pentobarbital $(50 \mathrm{mg} / \mathrm{kg}$, i.p.; Nacalai Tesque, Kyoto, Japan), mice were perfused with $4 \%$ paraformaldehyde solution in $0.01 \mathrm{M}$ phosphate buffer ( $\mathrm{pH}$ 7.4) for histological evaluation. Muscles were isolated, immersed in $4 \%$ paraformaldehyde solution for at least $24 \mathrm{~h}$ at $4^{\circ} \mathrm{C}$, and then soaked in $25 \%$ sucrose in phosphate-buffered saline (PBS) at $4^{\circ} \mathrm{C}$ for 1 day. Each sample was immersed sequentially in $70 \%$ ethanol ( $2 \mathrm{~h}), 90 \%$ ethanol $(2 \mathrm{~h}), 95 \%$ ethanol ( $2 \mathrm{~h}), 99 \%$ ethanol (12 h), anhydrous ethanol ( $2 \mathrm{~h}$ twice), xylene ( $2 \mathrm{~h}$ twice, $12 \mathrm{~h}$ ), and melted paraffin ( $2 \mathrm{~h}$ twice, $12 \mathrm{~h})$. Then, they were embedded in the paraffin and cut into $20-\mu \mathrm{m}$-thick sections using a microtome (Leica, Tokyo, Japan). After drying overnight at $37^{\circ} \mathrm{C}$, sections were stained with hematoxylin and eosin (Sigma-Aldrich, St. Louis, MO, USA). Histological images of these sections were obtained using a BZ-9000 HS all-in-one fluorescence microscope (Keyence, Osaka, Japan).

Cross-sectional area of muscle fibers. The transverse sections of gastrocnemius were cut at $3 \mathrm{~mm}$ from the edge of the gastrocnemius which was the largest transverse-section area, and the total and mean numbers of muscle fibers were evaluated. The transverse-section areas of muscle fibers were measured at the same position in each mouse. Images of the central positions of these sections were obtained using a microscope ( $20 \times$ magnification). The transverse-section areas of gastrocnemius were measured from 100 muscle fibers of each mouse using Image $\mathbf{J}$ software. The distribution of the muscle fiber area was quantified according to our previous procedures (16).

Cell culture. $\mathrm{C} 2 \mathrm{C} 12$ cells were purchased from the European Collection of Authenticated Cell Cultures (ECACC; Public Health England, UK), and cultured in accordance with the manufacturer protocol as follows. The cells were incubated in Dulbecco's modified Eagle medium (DMEM; Nacalai Tesque, Kyoto, Japan) supplemented with $10 \%$ fetal bovine serum (FBS; Thermo Fisher Scientific, Rockford, IL, USA), $100 \mathrm{U} / \mathrm{ml}$ penicillin (Meiji Seika
Kaisha Ltd., Tokyo, Japan), and $100 \mu \mathrm{g} / \mathrm{ml}$ streptomycin (Meiji Seika) under a humidified atmosphere of $5 \% \mathrm{CO}_{2}$ at $37^{\circ} \mathrm{C}$. The cells were passaged by trypsinazation every 2 days.

Immunostaining. Immunofluorescence staining in gastrocnemius was performed as follows. Under anesthesia with sodium pentobarbital $(80 \mathrm{mg} / \mathrm{kg}$, i.p.), mice were perfused with saline for $3 \mathrm{~min}$ and then with $4 \%$ paraformaldehyde solution (Nacalai Tesque, Kyoto, Japan) for $6 \mathrm{~min}$. Gastrocnemius were dissected and post-fixed in the same fixative solution for $24 \mathrm{~h}$ at $4{ }^{\circ} \mathrm{C}$. The tissues were soaked in a $25 \%$ sucrose solution for $24 \mathrm{~h}$ and quickly embedded in frozen embedding media (OCT compound, Sakura Finetechnical Co., Ltd., Tokyo, Japan). Finally, transverse sections were cut into $10-\mu \mathrm{m}$ thick on a cryostat and placed onto a coated glass slide (MAS COAT; Matsunami Glass Ind., Ltd., Osaka, Japan). The gastrocnemius sections were blocked with goat serum (Vector Labs, Burlingame, CA, USA) for $1 \mathrm{~h}$ and incubated with primary antibodies at $4^{\circ} \mathrm{C}$ overnight. As the primary antibodies for immunostaining, rabbit antiKi67 polyclonal antibody (1:250 dilution; Merk Millipore) and mouse anti-myoD monoclonal antibody (1:200 dilution; Santa Cruz) were used. After washing with PBS, the sections were incubated with a secondary antibody and Hoechst 33342 (1:1,000 dilution; H3570, Invitrogen) for $1 \mathrm{~h}$ at room temperature. Finally, the sections were mounted in a Fluoromount (Diagnostic BioSystems, Pleasanton, CA USA). As the secondary antibodies, Alexa Fluor ${ }^{\circledR} 546$ goat anti-rabbit $\operatorname{IgG}\left(1: 1,000\right.$ dilution; Invitrogen) and Alexa Fluor ${ }^{\circledR 5} 56$ goat antimouse $\operatorname{IgG}(1: 1,000$ dilution; Invitrogen) were used, respectively. Images of these sections were obtained using a BZ-9000 HS all-inone fluorescence microscope (Keyence, Osaka, Japan).

Immunofluorescence staining in $\mathrm{C} 2 \mathrm{C} 12$ was performed as follows. After washing with PBS, the plated cells were fixed in $4 \%$ paraformaldehyde solution (Nacalai Tesque, Kyoto, Japan) for 20 min at $4^{\circ} \mathrm{C}$, and then washed three times with PBS. To avoid nonspecific binding, the washed cells were then blocked using 5\% horse serum and $0.1 \%$ Triton X-100 (Nacalai Tesque, Kyoto, Japan) in PBS for $30 \mathrm{~min}$ at room temperature. The cells were washed with PBS and incubated with mouse anti-myosin heavy chain monoclonal antibody (1:400 dilution; MAB4470, R\&D) overnight at $4^{\circ} \mathrm{C}$. After primary antibody treatment, the cells were incubated with Alexa Fluor ${ }^{\circledR 5} 46$ donkey anti-mouse $\operatorname{IgG}(1: 1,000$ dilution; Invitrogen) and Hoechst 33342 (1:1,000 dilution; H3570, Invitrogen) for $1 \mathrm{~h}$ at room temperature. Images of these cells were obtained using a BZ-9000 HS all-in-one fluorescence microscope (Keyence, Osaka, Japan).

Western blot analysis. $\mathrm{C} 2 \mathrm{C} 12$ cells were lysed using radioimmunoprecipitation assay buffer containing $50 \mathrm{mM}$ Tris hydrochloride, $150 \mathrm{mM}$ sodium chloride, $0.5 \%$ sodium deoxycholate, $0.1 \%$ sodium dodecyl sulfate (SDS), $1 \%$ Igepal ${ }^{\circledR}$ CA-630, and protease and phosphatase inhibitor cocktails (Sigma-Aldrich, St. Louis, MO, USA). The cell lysates were centrifuged at $12,000 \times g$ for $10 \mathrm{~min}$, and the supernatants were obtained. Protein concentrations in the cell lysates were quantitated using the bicinchoninic acid protein assay kit (Pierce Biotechnology, Rockford, IL, USA). Equal volumes of cell lysate and sodium dodecyl sulfate (SDS) sample buffer containing 20\% 2-mercaptoethanol (Wako, Osaka, Japan) were mixed and boiled. The solubilized proteins were separated using 5-20\% SDS-polyacrylamide gel (Wako) electrophoresis, and transferred to an Immuno-Blot polyvinylidene fluoride membrane (Bio-Rad Laboratories, Hercules, CA, USA). The transferred 
membranes were incubated with the primary antibodies as follows: mouse anti-SMN monoclonal antibody (1:1,000 dilution; 610647, BD), rabbit anti-cleaved caspase-3 monoclonal antibody (1:200 dilution; Cell Signaling Technology), rabbit anti-p-Akt monoclonal antibody (1:1,000 dilution; Cell Signaling Technology), rabbit antiAkt monoclonal antibody (1:1,000 dilution; Cell Signaling Technology), mouse anti- $\beta$-actin mouse monoclonal antibody (1:2,000 dilution; A2228, Sigma-Aldrich), rabbit anti-p-JNK polyclonal antibody (1:500 dilution; SC6254, Santa Cruz). After washing with Tris-buffered saline with $0.05 \%$ Tween 20 , the transfers incubated with the secondary antibodies as follows: goat anti-rabbit and goat anti-mouse IgGs conjugated to horseradish peroxidase (1:1,000 dilution; 32460; Invitrogen; 1:1,000 dilution; 32430 , Thermo Scientific, respectively). The immunoreactive bands were visualized using a chemiluminescent substrate (ImmunoStar LD; Wako Pure Chemicals, Tokyo, Japan). The band intensities were measured using the Amersham Imager 680 Analysis Software (GE Healthcare Lifescience, Chicago, IL, USA).

Preparation of small interfering RNAs and differentiation for myotubes. All of the siRNAs were synthesized by Thermo Fisher Scientific (Invitrogen). The $\mathrm{C} 2 \mathrm{C} 12$ cells were transfected with $2 \mu \mathrm{M}$ of the siRNA using Lipofectamine ${ }^{\mathrm{TM}}$ RNAiMAX Reagent (Thermo Fisher Scientific) and Opti-MEM (Thermo Fisher Scientific) without serum supplement at $48 \mathrm{~h}$ after seeding. After transfection, the medium was changed to DMEM supplemented with $2 \%$ horse serum (Sigma-Aldrich) for differentiation.

Statistical analysis. Data are expressed as means \pm SEM. Statistical significance was evaluated using Levene's test for equality of variance followed by an appropriate $t$-test (Student's or Welch's $t$ test) using SPSS software 16.0 J (SPSS Japan, Inc., Tokyo, Japan).

\section{Results}

Skeletal muscle pathology in SMA model mice. SMA $\Delta 7$ mice, which exhibit a systemic decrease of SMN protein, are widely used as SMA model mice $(17,18)$. At the postnatal age day 11 (P11) developmental stage, during which mice show intermediate symptoms, $\mathrm{SMN} \Delta 7$ mice exhibited reduced body mass compared to wild-type mice (Figure 1A and B). Gastrocnemius were isolated at P11 for evaluation of fiber cross-sectional area and expression of differentiationrelated factor. Fiber cross-sectional area was significantly decreased in SMN $\Delta 7$ mice compared to wild-type mice (Figure 1C-E). MyoD, the master regulator of skeletal muscle cell differentiation, was detected by immunostaining. MyoDpositive cells were significantly decreased to $26 \%$ in gastrocnemius of SMN $\Delta 7$ mice compared to wild-type mice (Figure $1 \mathrm{H}$ and I). In addition, Ki67-positive proliferative cells were also decreased to $24 \%$ in $\operatorname{SMN} \Delta 7$ mice compared to wild-type mice (Figure 1F and G).

Impaired maturation in SMN-depleted myoblasts. To investigate the role of SMN protein in skeletal muscle cell maturation, we used SMN-knockdown myoblasts, which can ignore the effect of denervation. Mouse myoblasts $\mathrm{C} 2 \mathrm{C} 12$ cells were transfected with Smn siRNA. After transfection, C2C12 cells were cultured in differentiation medium for 48 to $96 \mathrm{~h}$, and the expression levels of SMN and myosin heavy chain (MHC) were evaluated by western blotting. SMN protein was significantly decreased by Smn siRNA transfection (Figure 2A and B), and the significant reduction of SMN protein was sustained for at least 6 days after transfection (data not shown). In contrast, MHC expression was increased with cell differentiation in a time-dependent manner. The MHC expression was significantly facilitated in SMN-knockdown C2C12 cells compared to control siRNA transfected $\mathrm{C} 2 \mathrm{C} 12$ cells at $48 \mathrm{~h}$ after initiating differentiation, whereas no change in MHC expression was observed at 72 or $96 \mathrm{~h}$ after initiating differentiation (Figure 2A and C). Myoblasts differentiate into myotubes and muscle fibers. At these differentiation stages, cell-cell fusion and formation of multinucleated fibers is a key step $(19,20)$. To investigate the level of cell-fusion, we evaluated the average number of nuclei in differentiated $\mathrm{C} 2 \mathrm{C} 12$ cells. As a result, the average number of nuclei was decreased in SMN-knockdown C2C12 cells (Figure 2D and E), suggesting an impairment of myoblast maturation by SMN-knockdown. In addition, a decrease in cell-autonomous contractions was observed at 6 days, indicating decreased differentiation in SMN-knockdown C2C12 cells compared to control cells (Supplementary Video 1 and Supplementary Video 2).

Decreased caspase-3 activation in SMN-knockdown C2C12 cells. To elucidate the mechanism of impaired fusion in SMNknockdown $\mathrm{C} 2 \mathrm{C} 12$ cells, we evaluated the expression level of cleaved-caspase- 3 by western blotting. Caspase- 3 activation is required for normal skeletal muscle differentiation (21). In control cells, the expression level of cleaved-caspase-3 was decreased as differentiation progressed (Figure 3A and B). Cleaved-caspase-3 was highly expressed in the early phase of differentiation, and it was significantly decreased in SMNknockdown C2C12 cells compared to control cells at $72 \mathrm{~h}$ after inducing differentiation (Figure $3 \mathrm{~A}$ and $\mathrm{B}$ ).

Akt signaling is a key regulatory process for skeletal muscle differentiation and hypertrophy (22). We examined the involvement of Akt activation in impaired maturation in SMNknockdown myoblasts. An equivalent level of phosphorylated Akt was observed in SMN-knockdown and control C2C12 cells at $48 \mathrm{~h}$ after initiating differentiation (Figure 4A and B). In contrast, phosphorylated Akt was decreased in SMNknockdown $\mathrm{C} 2 \mathrm{C} 12$ cells compared to controls at $72 \mathrm{~h}$ after initiating differentiation (Figure $4 \mathrm{~A}$ and $\mathrm{B}$ ).

\section{Discussion}

SMN protein is considered to play an important role in the maturation of skeletal muscle cells by cell-autonomous mechanisms. However, the fundamental function of SMN 


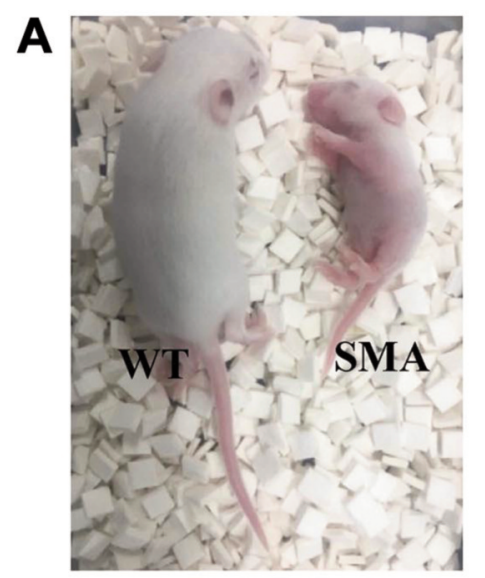

B

C
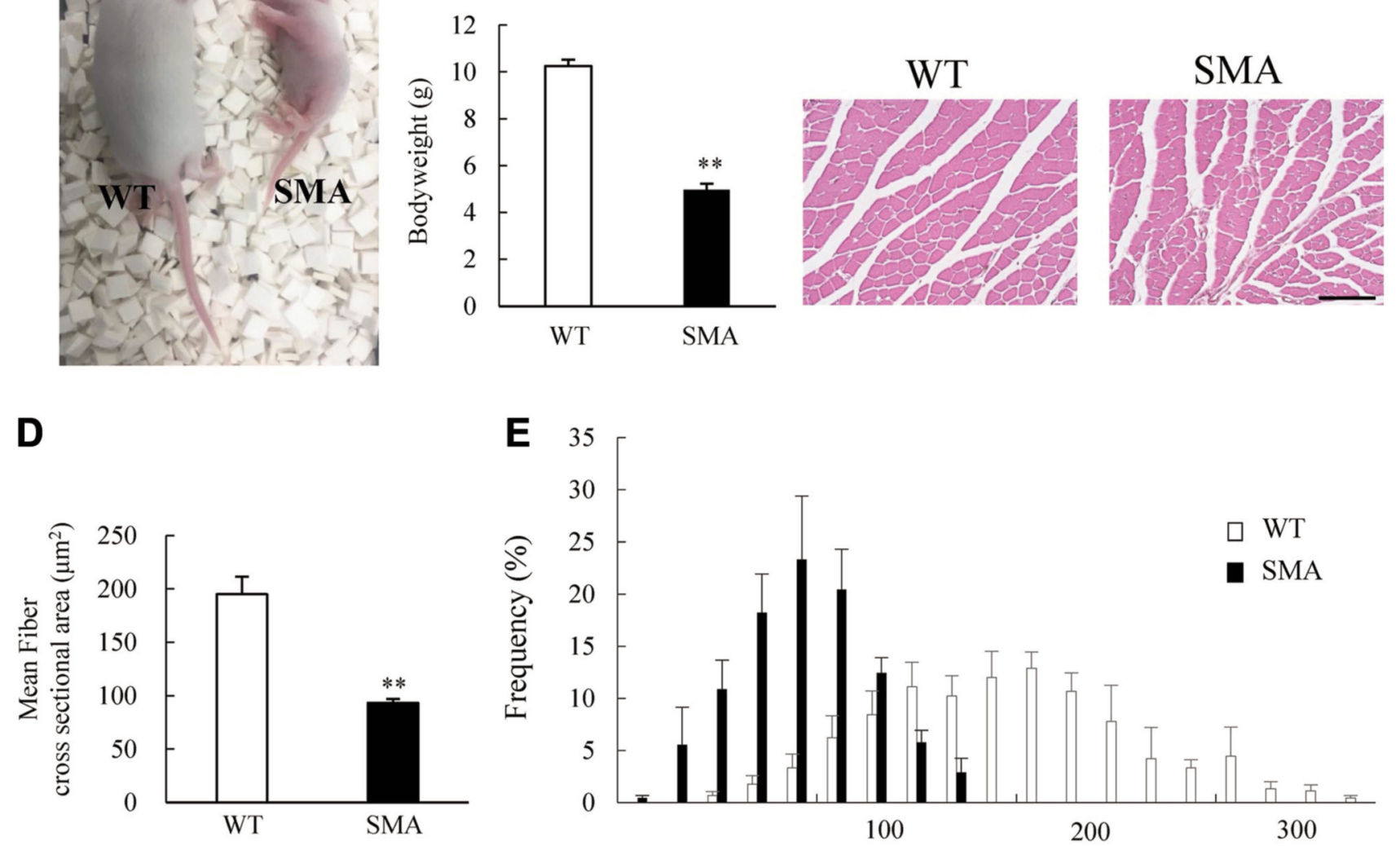

F

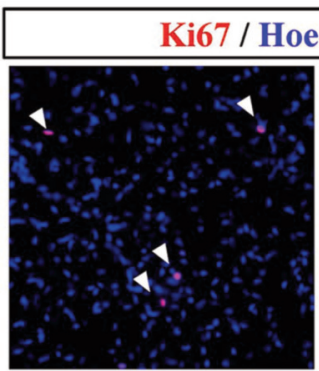

WT

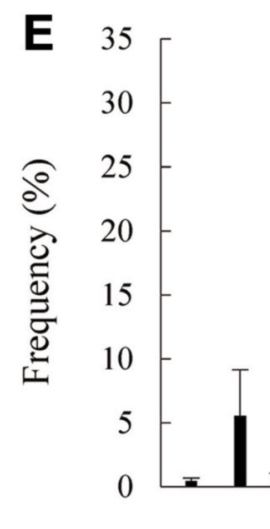

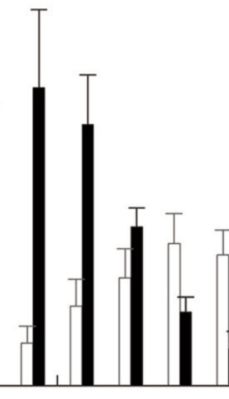

100

Fiber cross sectional area $\left(\mu \mathrm{m}^{2}\right)$

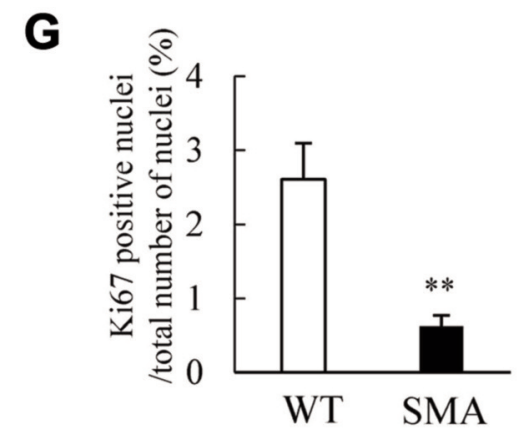

Figure 1. Continued

protein underlying the maturation of skeletal muscle cells is still unknown. In the present study, we first evaluated the expression of a myogenesis marker and a proliferating marker and observed a decrease in MyoD-positive cells and ki67-positive cells in skeletal muscle SMN $\Delta 7$ mice at P11 (Figure 1). These results suggest reduced ability for myogenesis in the skeletal muscles of SMA model mice, in concordance with previous reports that suggested immaturity of skeletal muscles in SMA $(10,23)$. However, skeletal muscle denervation has been found in $\operatorname{SMN} \Delta 7$ mice by at least P7 (24). Hence, our observation is considered to be due to both denervation and the cell-autonomous function of $\mathrm{SMN}$ in skeletal muscle cells.

Next, we investigated the role of SMN protein in skeletal muscle cell maturation using SMN-knockdown myoblasts, which can ignore the effect of denervation. Earlier expression of MHC protein was observed in SMN-knockdown C2C12 cells, suggesting quicker differentiation by SMN-knockdown. 


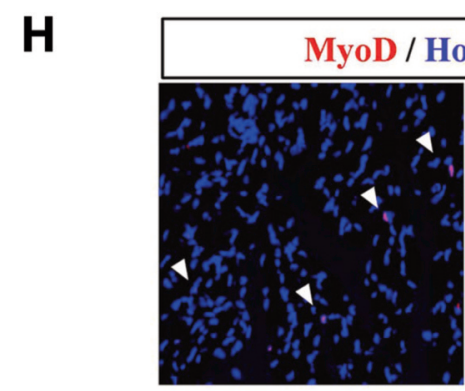

WT

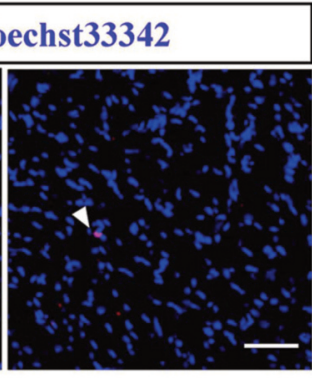

SMA

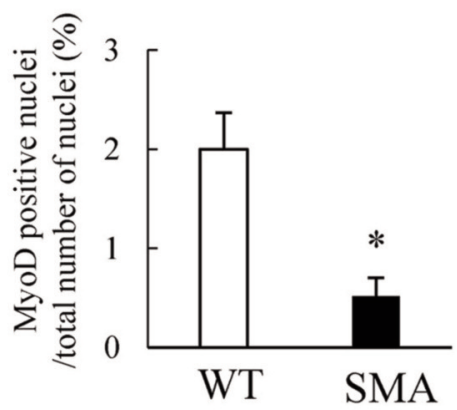

Figure 1. Skeletal muscle pathology in spinal muscular atrophy (SMA) model mice. (A) Images of wild-type (WT) and SMN 47 mice at P11 which show intermediate symptoms, $(B)$ Body weight of WT and SMNA7 mice at P11. Data are presented as means $\pm S . E . M$. (WT mice: $n=4 ;$; SMNA7 mice: $n=3$ ). ${ }^{* *} p<0.01 \mathrm{vs}$. WT mice (Student's t-test). (C) Representative hematoxylin and eosin staining for gastrocnemius of WT and SMN 47 mice at P11. Scale bar $=100 \mu \mathrm{m}$. (D) Mean fiber cross-sectional area. Data are presented as means $\pm S . E . M$. (WT mice: $n=4 ;$ SMN $\Delta 7$ mice: $n=3)$. **p<0.01 vs. WT mice (Student's $t$-test). (E) The distribution of fiber cross-sectional area. Data are presented as mean \pm S.E.M. (WT mice: $n=4$; SMNA7 mice: $n=3)$. (F) Representative fluorescence images of Ki67 in gastrocnemius of WT and SMNA7 mice at P11. Scale bar=75 $\mu$ m. (G) Quantitative analysis of Ki67-positive cells. Data are presented as means \pm S.E.M. (WT mice: $n=4$; SMN 47 mice: $n=4)$ ).** $p<0.01$ vs. WT mice (Student's t-test). (H) Representative fluorescence images of MyoD in gastrocnemius of WT and SMNA7 mice at P11. Scale bar=75 $\mu m$. (I) Quantitative analysis of MyoDpositive cells. Data are presented as means \pm S.E.M. (WT mice: $n=4$; SMN $\Delta 7$ mice: $n=4)$. *p<0.05 vs. WT mice (Student's t-test).
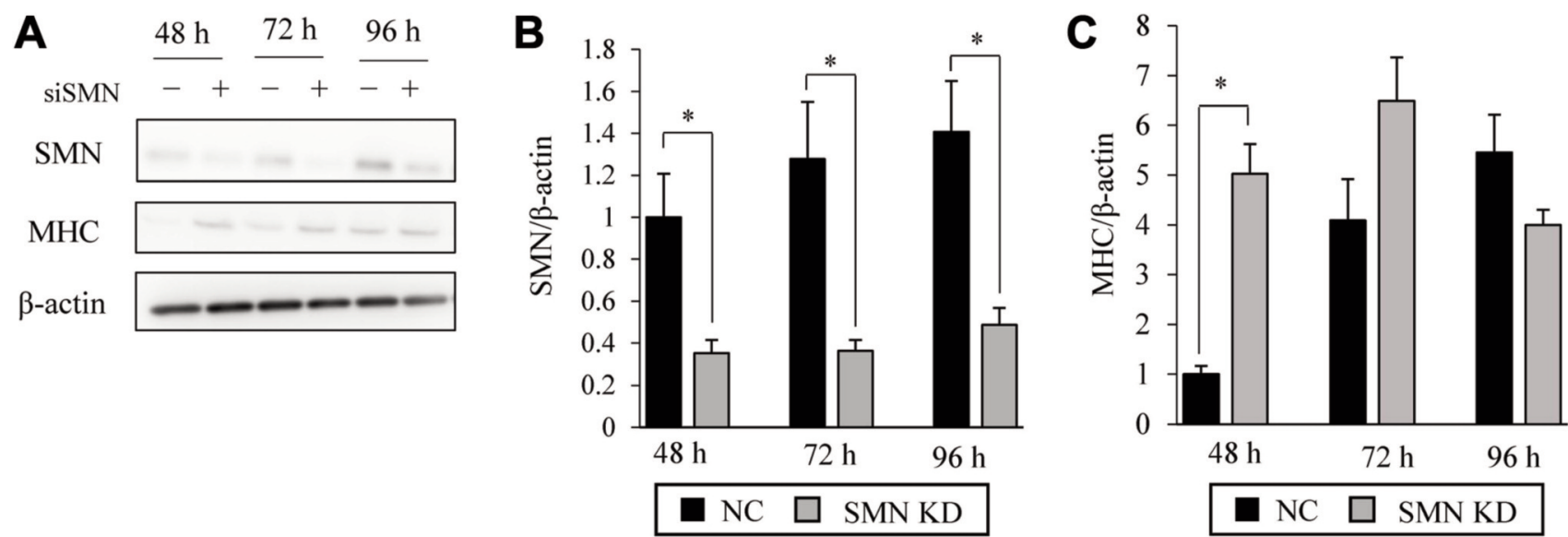

D

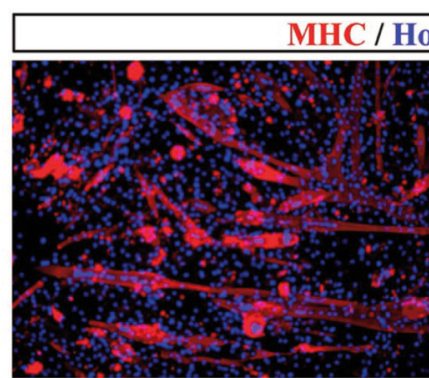

$\mathrm{NC}$

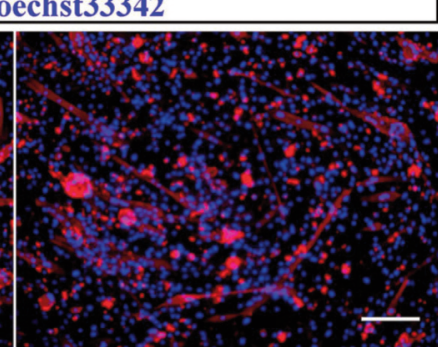

SMN KD

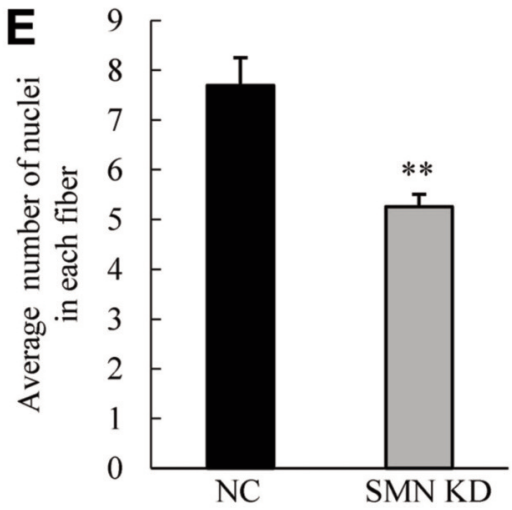

Figure 2. Altered expression of myosin heavy chain (MHC) and impaired fusion in SMN-knockdown C2C12 cells. (A) MHC and SMN protein expression was examined by western blot analysis in C2C12 cells. (B) Quantitative analysis of the expression level of SMN protein. Data are presented as means \pm S.E.M. $(n=5$ or 7$),{ }^{*} p<0.05,{ }^{*} p<0.01 \mathrm{vs}$. Negative Control siRNA group (Welch's $t$-test). (C) Quantitative analysis of the expression level of MHC. Data are presented as mean \pm S.E.M. ( $n=5$ or 7$), * p<0.05$ vs. Negative Control siRNA group (Welch's t-test). (D) Representative fluorescence image of MHC 6 days after transfection of siRNA. Scale bar=200 $\mu m$. (E) Quantitative analysis of the mean number of nuclei in each fiber. Data are presented as means \pm S.E.M. $(n=8) . *^{*} p<0.01 \mathrm{vs}$. Negative Control siRNA group (Student's t-test). 
A

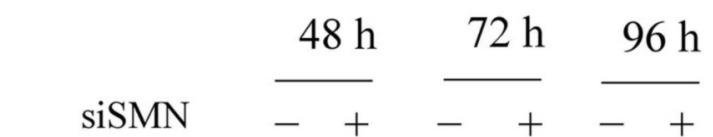

\section{Cleaved- caspase 3}

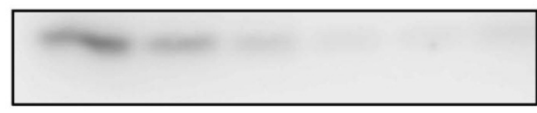

\section{SMN}

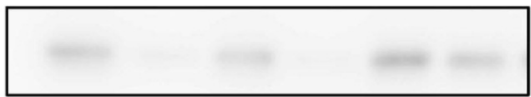

$\beta$-actin

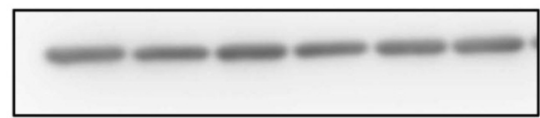

B

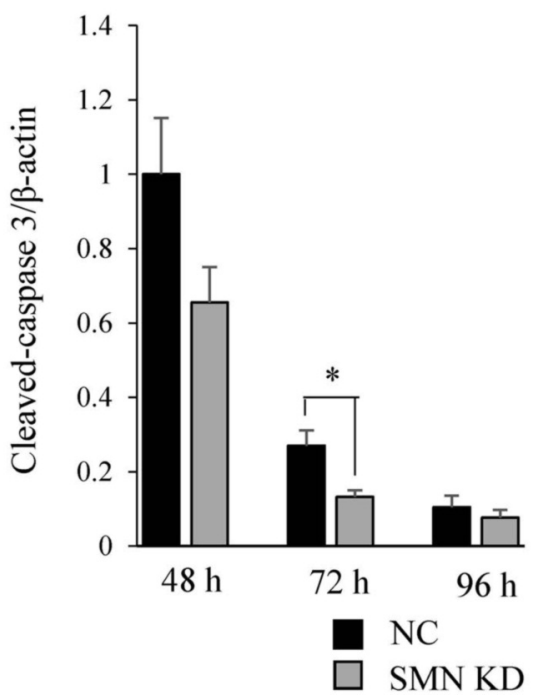

Figure 3. Impaired caspase-3 activation during differentiation in SMNknockdown C2C12 cells. (A) Cleaved-caspase-3 and SMN protein expression was examined by western blot analysis in $\mathrm{C} 2 \mathrm{C} 12$ cells. (B) Quantitative analysis of the expression level of cleaved-caspase-3. Data are presented as means \pm S.E.M. $(n=5$ or 7$)$. ${ }^{* *} p<0.01$ vs. Negative Control siRNA group (Student's t-test).

Similar findings using SMN $\Delta 7$ derived muscle cells have been reported $(12,25)$. Importantly, the ability to form multinuclei myotubes was reduced in SMN-knockdown $\mathrm{C} 2 \mathrm{C} 12$ cells (Figure 2). This result is in concordance with impaired myotube formation in SMN $\Delta 7$-derived muscle cells and SMNknockdown C2C12 cells using shRNA $(12,13,25)$. Contraction ability is also one of the key factors reflecting skeletal muscle maturation, and a reduction of cell-autonomous contraction was observed in SMN-knockdown C2C12 cells (Supplementary video 1,2$)$. Therefore, SMN protein is required for normal myotube maturation, and inadequate timing of MHC expression may contribute to impaired myotube formation.

Caspase-3 is known as an effector of typical intracellular changes in apoptosis (26). However,
A
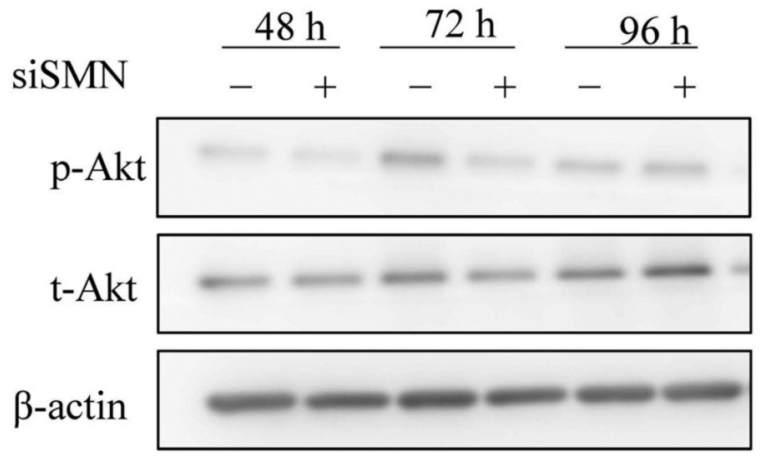

B

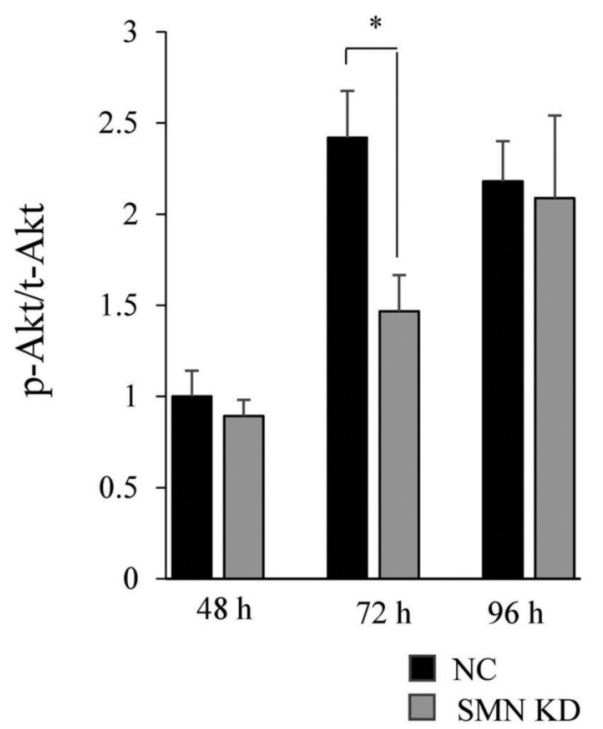

Figure 4. Impaired Akt activation during differentiation in SMNknockdown C2C12 cells. (A) p-Akt and total Akt expression was examined by western blot analysis in C2C12 cells. (B) Quantitative analysis of the expression level of $p$-Akt and total Akt. Data are presented as means $\pm S . E . M .(n=5$ or 7$)$. ${ }^{*} p<0.05$ vs. Negative Control siRNA group (Student's t-test).

inhibition of caspase- 3 activity in myoblasts results in a dramatic reduction in multinuclei myotube formation and expression of muscle-specific proteins (21). Therefore, caspase- 3 activation is required for effective differentiation in myoblasts. In SMN-knockdown $\mathrm{C} 2 \mathrm{C} 12$ cells, caspase-3 activity was decreased in the early phase of differentiation (Figure 3). Hence, impaired activation of caspase- 3 by SMN-knockdown may contribute to the reduced ability for multinuclei myotube formation, observed in Figure 2. In contrast, deficiency of SMN protein in motor neurons leads to caspase- 3 activation and subsequent apoptosis (27, 28). Therefore, the mechanism of regulation for caspase- 3 activity by SMN protein may differ between myoblasts and motor neurons. 
In the present study, impaired activation of Akt was observed in SMN-knockdown C2C12 cells (Figure 4). The Akt/mTOR pathway contributes to skeletal muscle differentiation and hypertrophy via protein synthesis $(22$, 29). It was reported that the expression of mature acetylcholine receptor subunits was delayed in the skeletal muscles of SMA model mice (23). In SMN-knockdown C2C12 cells, decreased cell-autonomous contraction was observed (Supplementary Video 1 and 2). Therefore, decreased activation of Akt is considered responsible for the impaired maturation of SMN-knockdown myoblasts.

Impaired muscle cell differentiation and proliferation was observed in SMN $\Delta 7$ mice, and impaired maturation was also observed in SMN-knockdown C2C12 cells. Furthermore, activation of caspase-3 and Akt was suppressed by SMNknockdown. These results are important findings that suggest the need for therapeutic intervention of SMN proteins into skeletal muscle in SMA pathology. However, we could not show that the SMN knockdown-induced reduction of caspase- 3 and Akt is directly involved in muscle differentiation, and further investigation is needed. In conclusion, these findings provide new evidence for a role of SMN protein in skeletal muscle cell differentiation.

\section{Conflicts of Interest}

The Authors have no conflicts of interest to disclose in regard to this study.

\section{Authors' Contributions}

SN, MS and HH contributed to the conception and design of the study. $\mathrm{SA}, \mathrm{MT}$, and NC did the acquisition, analysis, and interpretation of data. SA, MS and HH drafted the work and critically revised it. SA, MT, NC, SN, MS and HH approved the final version to be published. SA, MT, NC, SN, MS and HH agreed on all aspects of the work.

\section{Supplementary Material}

Video 1. Cell-autonomous contraction in differentiated $\mathrm{C} 2 \mathrm{C} 12$ cells at 6 days after control siRNA treatment. Available at: http://sv1.gifupu.ac.jp/lab/seitaikinou/files/2020/07/Supplemental-movie1_Control-siRNA.wmv

Video 2. Cell-autonomous contraction in differentiated $\mathrm{C} 2 \mathrm{C} 12$ cells at 6 days after SMN siRNA treatment. Available at: http://sv1.gifupu.ac.jp/lab/seitaikinou/files/2020/07/Supplemental-movie-2_SmnsiRNA.wmv

\section{References}

1 Lefebvre S, Burglen L, Reboullet S, Clermont O, Burlet P, Viollet L, Benichou B, Cruaud C, Millasseau P, Zeviani M, Le Paslier D, Frézal J, Cohen D, WeissenbachJ, Munnich A and Melki J: Identification and characterization of a spinal muscular atrophy-determining gene. Cell 80(1): 155-165, 1995. PMID: 7813012. DOI: 10.1016/0092-8674(95)90460-3
2 Crawford TO and Pardo CA: The neurobiology of childhood spinal muscular atrophy. Neurobiol Dis 3(2): 97-110, 1996. PMID: 9173917. DOI: 10.1006/nbdi.1996.0010

3 Sumner CJ: Molecular mechanisms of spinal muscular atrophy. J Child Neurol 22(8): 979-989, 2007. PMID: 17761653. DOI: $10.1177 / 0883073807305787$

4 Hahnen E, Forkert R, Marke C, Rudnik-Schoneborn S, Schonling J, Zerres K and Wirth B: Molecular analysis of candidate genes on chromosome $5 \mathrm{q} 13$ in autosomal recessive spinal muscular atrophy: Evidence of homozygous deletions of the SMN gene in unaffected individuals. Hum Mol Genet 4(10): 1927-1933, 1995. PMID: 8595417. DOI: 10.1093/hmg/4.10.1927

5 Gennarelli M, Lucarelli M, Capon F, Pizzuti A, Merlini L, Angelini C, Novelli G and Dallapiccola B: Survival motor neuron gene transcript analysis in muscles from spinal muscular atrophy patients. Biochem Biophys Res Commun 213(1): 342348, 1995. PMID: 7639755. DOI: 10.1006/bbrc.1995.2135

6 Lorson CL, Hahnen E, Androphy EJ and Wirth B: A single nucleotide in the SMN gene regulates splicing and is responsible for spinal muscular atrophy. Proc Natl Acad Sci USA 96(11): 6307-6311, 1999. PMID: 10339583. DOI: 10.1073/pnas. 96.11.6307

7 Pellizzoni L, Kataoka N, Charroux B and Dreyfuss G: A novel function for SMN, the spinal muscular atrophy disease gene product, in pre-mRNA splicing. Cell 95(5): 615-624, 1998. PMID: 9845364. DOI: 10.1016/s0092-8674(00)81632-3

8 Donlin-Asp PG, Bassell GJ and Rossoll W: A role for the survival of motor neuron protein in mRNP assembly and transport. Curr Opin Neurobiol 39: 53-61, 2016. PMID: 27131421. DOI: 10.1016/j.conb.2016.04.004

9 Hua Y, Sahashi K, Rigo F, Hung G, Horev G, Bennett CF and Krainer AR: Peripheral SMN restoration is essential for longterm rescue of a severe spinal muscular atrophy mouse model. Nature 478(7367): 123-126, 2011. PMID: 21979052. DOI: 10.1038/nature 10485

10 Lee YI, Mikesh M, Smith I, Rimer M and Thompson W: Muscles in a mouse model of spinal muscular atrophy show profound defects in neuromuscular development even in the absence of failure in neuromuscular transmission or loss of motor neurons. Dev Biol 356(2): 432-444, 2011. PMID: 21658376. DOI: 10.1016/j.ydbio.2011.05.667

11 Cifuentes-Diaz C, Frugier T, Tiziano FD, Lacene E, Roblot N, Joshi V, Moreau MH and Melki J: Deletion of murine SMN exon 7 directed to skeletal muscle leads to severe muscular dystrophy. J Cell Biol 152(5): 1107-1114, 2001. PMID: 11238465. DOI: $10.1083 /$ jcb.152.5.1107

12 Hayhurst M, Wagner AK, Cerletti M, Wagers AJ and Rubin LL: A cell-autonomous defect in skeletal muscle satellite cells expressing low levels of survival of motor neuron protein. Dev Biol 368(2): 323-334, 2012. PMID: 22705478. DOI: 10.1016/ j.ydbio.2012.05.037

13 Shafey D, Cote PD and Kothary R: Hypomorphic Smn knockdown $\mathrm{C} 2 \mathrm{C} 12$ myoblasts reveal intrinsic defects in myoblast fusion and myotube morphology. Exp Cell Res 311(1): 49-61, 2005. PMID: 16219305. DOI: 10.1016/j.yexcr.2005.08.019

14 Guettier-Sigrist S, Coupin G, Braun S, Rogovitz D, Courdier I, Warter JM and Poindron P: On the possible role of muscle in the pathogenesis of spinal muscular atrophy. Fundam Clin Pharmacol 15(1): 31-40, 2001. PMID: 11468011. DOI: 10.1046/ j.1472-8206.2001.00006.x 
15 Ohuchi K, Funato M, Yoshino Y, Ando S, Inagaki S, Sato A, Kawase C, Seki J, Saito T, Nishio H, Nakamura S, Shimazawa M, Kaneko $\mathrm{H}$ and Hara $\mathrm{H}$ : Notch signaling mediates astrocyte abnormality in spinal muscular atrophy model systems. Sci Rep 9(1): 3701, 2019. PMID: 30842449. DOI: 10.1038/s41598-01939788-w

16 Nagahara Y, Shimazawa M, Tanaka H, Ono Y, Noda Y, Ohuchi K, Tsuruma K, Katsuno M, Sobue G and Hara H: Glycoprotein nonmetastatic melanoma protein $\mathrm{B}$ ameliorates skeletal muscle lesions in a SOD1(G93A) mouse model of amyotrophic lateral sclerosis. J Neurosci Res 93(10): 1552-1566, 2015. PMID: 26140698. DOI: $10.1002 /$ jnr.23619

17 Butchbach ME, Edwards JD and Burghes AH: Abnormal motor phenotype in the SMNdelta7 mouse model of spinal muscular atrophy. Neurobiol Dis 27(2): 207-219, 2007. PMID: 17561409. DOI: $10.1016 /$ j.nbd.2007.04.009

18 Le TT, Pham LT, Butchbach ME, Zhang HL, Monani UR, Coovert DD, Gavrilina TO, Xing L, Bassell GJ and Burghes AH: SMNdelta7, the major product of the centromeric survival motor neuron (SMN2) gene, extends survival in mice with spinal muscular atrophy and associates with full-length SMN. Hum Mol Genet 14(6): 845-857, 2005. PMID: 15703193. DOI: 10.1093/hmg/ddi078

19 Abmayr SM and Pavlath GK: Myoblast fusion: Lessons from flies and mice. Development 139(4): 641-656, 2012. PMID: 22274696. DOI: $10.1242 / \mathrm{dev} .068353$

20 Rochlin K, Yu S, Roy S and Baylies MK: Myoblast fusion: When it takes more to make one. Dev Biol 341(1): 66-83, 2010. PMID: 19932206. DOI: 10.1016/j.ydbio.2009.10.024

21 Fernando P, Kelly JF, Balazsi K, Slack RS and Megeney LA: Caspase 3 activity is required for skeletal muscle differentiation. Proc Natl Acad Sci USA 99(17): 11025-11030, 2002. PMID: 12177420. DOI: $10.1073 /$ pnas.162172899

22 Bodine SC, Stitt TN, Gonzalez M, Kline WO, Stover GL, Bauerlein R, Zlotchenko E, Scrimgeour A, Lawrence JC, Glass DJ and Yancopoulos GD: Akt/mTOR pathway is a crucial regulator of skeletal muscle hypertrophy and can prevent muscle atrophy in vivo. Nat Cell Biol 3(11): 1014-1019, 2001. PMID: 11715023. DOI: $10.1038 / \mathrm{ncb} 1101-1014$

23 Kong L, Wang X, Choe DW, Polley M, Burnett BG, BoschMarce M, Griffin JW, Rich MM and Sumner CJ: Impaired synaptic vesicle release and immaturity of neuromuscular junctions in spinal muscular atrophy mice. J Neurosci 29(3): 842-851, 2009. PMID: 19158308. DOI: 10.1523/JNEUROSCI. 4434-08.2009
24 Murray LM, Comley LH, Thomson D, Parkinson N, Talbot K and Gillingwater TH: Selective vulnerability of motor neurons and dissociation of pre- and post-synaptic pathology at the neuromuscular junction in mouse models of spinal muscular atrophy. Hum Mol Genet 17(7): 949-962, 2008. PMID: 18065780. DOI: $10.1093 / \mathrm{hmg} / \mathrm{ddm} 367$

25 Bricceno KV, Martinez T, Leikina E, Duguez S, Partridge TA, Chernomordik LV, Fischbeck KH, Sumner CJ and Burnett BG: Survival motor neuron protein deficiency impairs myotube formation by altering myogenic gene expression and focal adhesion dynamics. Hum Mol Genet 23(18): 4745-4757, 2014. PMID: 24760765. DOI: $10.1093 / \mathrm{hmg} / \mathrm{ddu} 189$

26 Alnemri ES: Mammalian cell death proteases: A family of highly conserved aspartate specific cysteine proteases. J Cell Biochem 64(1): 33-42, 1997. PMID: 9015752. DOI: 10.1002/(sici)10974644(199701)64:1<33::aid-jcb6>3 .0 .co;2-0

27 Ohuchi K, Funato M, Kato Z, Seki J, Kawase C, Tamai Y, Ono Y, Nagahara Y, Noda Y, Kameyama T, Ando S, Tsuruma K, Shimazawa M, Hara $\mathrm{H}$ and Kaneko H: Established stem cell model of spinal muscular atrophy is applicable in the evaluation of the efficacy of thyrotropin-releasing hormone analog. Stem Cells Transl Med 5(2): 152-163, 2016. PMID: 26683872. DOI: 10.5966/sctm.2015-0059

28 Parker GC, Li X, Anguelov RA, Toth G, Cristescu A and Acsadi G: Survival motor neuron protein regulates apoptosis in an in vitro model of spinal muscular atrophy. Neurotox Res 13(1): 3948, 2008. PMID: 18367439. DOI: 10.1007/BF03033366

29 Vandromme M, Rochat A, Meier R, Carnac G, Besser D, Hemmings BA, Fernandez A and Lamb NJ: Protein kinase B beta/Akt2 plays a specific role in muscle differentiation. J Biol Chem 276(11): 8173-8179, 2001. PMID: 11087731. DOI: 10.1074/jbc.M005587200
Received July 18, 2020

Revised July 29, 2020

Accepted August 3, 2020 